\title{
Automatic inspection system for dimensional measurements of the saw blade milling cutter
}

\author{
Yung-Cheng Wang ${ }^{1}$, Jui-Chang Lin ${ }^{2}$, Shih-Fong Chiu ${ }^{1}$ \\ ${ }^{1}$ National Yunlin University of Science and Technology, Institute of Mechanical Engineering \\ (TAIW AN); ${ }^{2}$ National Formosa University, Department of Mechanical Design Engineering \\ (TAIWAN) \\ wangyc@yuntech.edu.tw; linr@@,nfu.edu.tw;.wing363636@,hotmail.com
}

Received February 2010

Accepted October 2010

\begin{abstract}
The demand for measuring equipments of automatic optical inspection has grown rapidly, because of its benefits of promoted efficiency and higher precision. Instead of manual projection measurements, measurement performance and efficiency can be obviously enhanced by the image measurement system. In this investigation, digital image processing and geometrical measurement principles have been integrated to develop a dynamic measurement system for the dimensional measurements of a saw blade milling cutter. The repeatability of the measurement system has been analyzed and its accuracy has been verified by using commercial 3D image measurement system. The analysis results show that the dimensional precision of $25 \mu \mathrm{m}$ and the angular precision of $0.21^{\circ}$ can be realized by the self-developed measurement system. Between the results of the developed system and reference standard system, there are $25 \mu \mathrm{m}$ deviation in dimensional measurement and $0.26^{\circ}$ in angular measurement. That measuring performances can meet the industrial requirement and the higher measurement efficiency can be achieved.
\end{abstract}

Keywords: dimensional measurement, saw blade milling cutter, repeatability and accuracy 


\section{Introduction}

For advanced manufacture and quality control in the mechanical industry, it is necessary to dominate concerning methods for the product inspection.

Although currently many inspection machines or instruments have been offered for $2 \mathrm{D}$ or $3 \mathrm{D}$ dimensional measurements, but there is no proper automation inspection system for the dimensional measurement of the saw blade milling cutter whose quality will remarkably influence the precision of saw blades produced by it. Hence no accurate data can be provided for correction or compensation when the saw blade milling cutter is processed. Generally the dimensions of saw blade milling cutters could be verified by that of saw blades processed by the milling cutter, after saw blades have been inspected by the optical projector. According to the dimensional results acquired by the indirect measurement method, the concerning dimensions could be compensated and the saw blade milling cutter would be ground correctly.

With this above-mentioned method, dimensional and angular measurement errors have been often induced. Because considerable teeth of a saw blade need to be inspected, it will be inefficiency and there will also be manual errors resulting from analysis of the inspector during the manual procedure. Therefore, the inspection results could not concretely reveal the quality of a saw blade milling cutter.

In this investigation on the dimensional measurement of the saw blade milling cutter, an image inspection system has been developed by integrating the image measurement technology, CCD, backlight panel of LED, rotary shaft of servo motor and $x-y$ biaxial stage. By the system, the image position of some points in a saw blade milling cutter can be automatically acquired and then dimensional parameters can be estimated with aid of the self-developed measuring program. The error of the manual operation would be significantly minimized. The measuring parameters of a saw blade milling cutter consist of tooth pitch, processing height, height of a full tooth, radius of a tooth top and pressure angle.

The quantitative measurement results can be provided for the positioning compensation of the processing machine to realize the more accurate dimensions of a processed saw blade. With this new measurement function, the efficiency and accuracy can be obviously enhanced. 


\section{Measurement principle}

\subsection{I mage threshold processing}

Threshold processing is one of the important methods in the image segmentation. With the gray-scale threshold, the image pixels are divided into two groups to distinguish the object area from the background area. The gray-scale image of a saw blade milling cutter is illustrated in figure 1(a). From the example, a threshold value $\left(T_{0}\right)$ based on the gray scale histogram is set which distinguishes between the most obvious object and the background, where threshold would be decided by Otsu's method (Gonzalez \& Woods, 2002; Otsu, 1979). After this analysis process, its gray-scale histogram (Fig.2) has been schemed. In comparison with the threshold value, it will be altered to the gray-scale value of 255 , if the gray-scale value of an image pixel is greater than this critical value. Otherwise, the gray-scale value will be modified to 0 , as expressed in equation 1 . After the diagnosis process, the binary image of a saw blade milling cutter (Fig.1 (b)) can be derived. The image quality becomes better and it will be benefit for the accurate determination of the measuring object boundary.

$$
\mathrm{f}_{\mathrm{T}}(\mathrm{x}, \mathrm{y})=\begin{gathered}
255 \text { if } \mathrm{f}(\mathrm{x}, \mathrm{y})>\mathrm{T}_{0} \\
0 \text { if } \mathrm{f}(\mathrm{x}, \mathrm{y}) \leq \mathrm{T}_{0}
\end{gathered}
$$

Equation 1. "Equation of the threshold value".

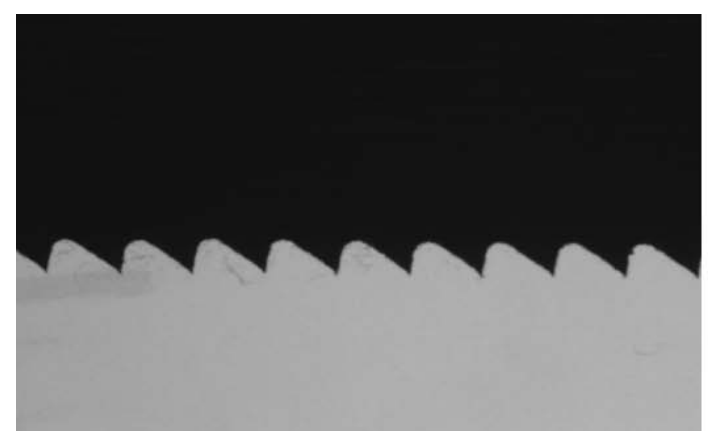

(a) Gray-scale image of a saw blade milling cutter

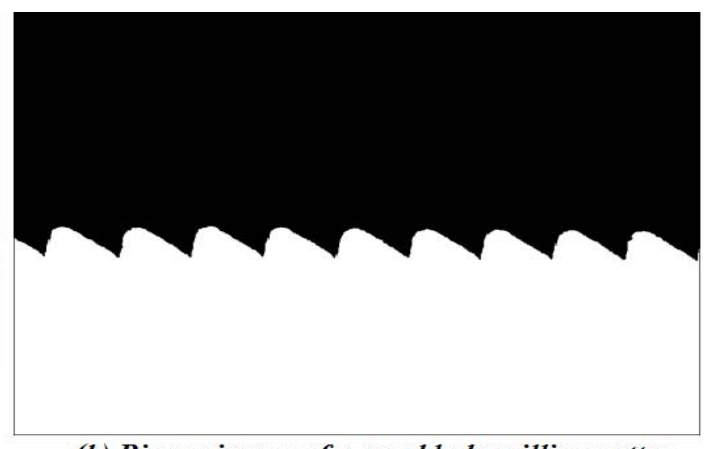

(b) Binary image of a saw blade milling cutter

Figure 1. "Gray-scale image and binary image of a saw blade milling cutter". 


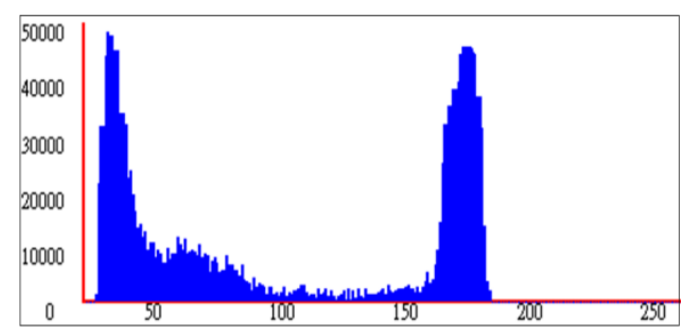

Figure 2. "Gray-scale histogram".

\subsection{I mage filtering}

Medium value filter (median filter) has been proved to be an effective method to eliminate image noise (Wang et al., 2009). Besides noise elimination, it has the advantage of preserving the image contrast. By a mask, the pixel value inside the mask is rearranged.

For example, a $3 \times 3$ mask median filter is indicated in figure 3 . There are nine pixels (S1, S2 ... S9) in this mask and their pixel values are shown in the array. According to the result of sequencing sorting the values, the median value can be obtained. After analysis, the median is the value 29. By replacing the original ( $x, y)$ position of the pixel value with 29 , the process is known as median filtering (Otsu, 1979; Scaman \& Economikos, 1995).

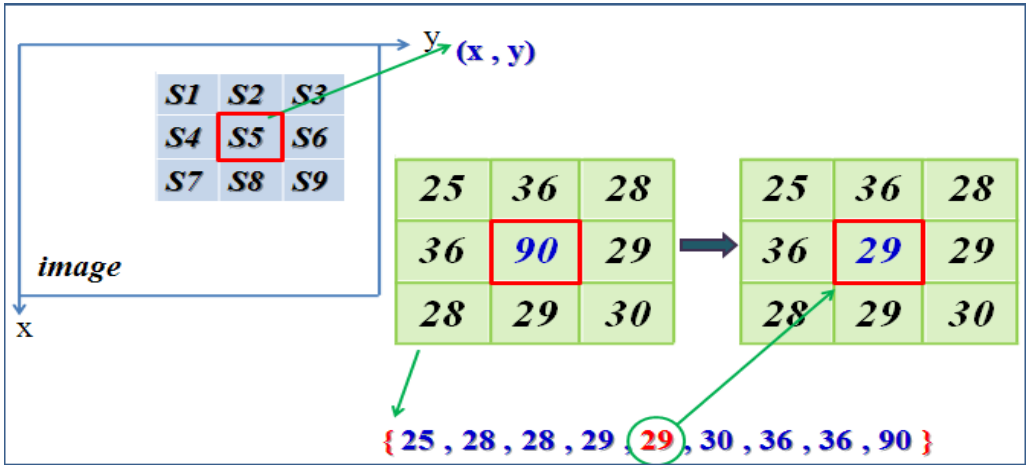

Figure 3. "Median filter processing".

\subsection{Light source}

Illumination intensity is an important factor affecting the image quality and the measurement accuracy. The illumination system can be classified into two types: front light and back light source. Here the back light source has been selected for the image measurement (Fig. 4), because back light model is appropriate to 
distinguish the object and the background and would be better for determination of the profile boundary of a saw blade milling cutter.

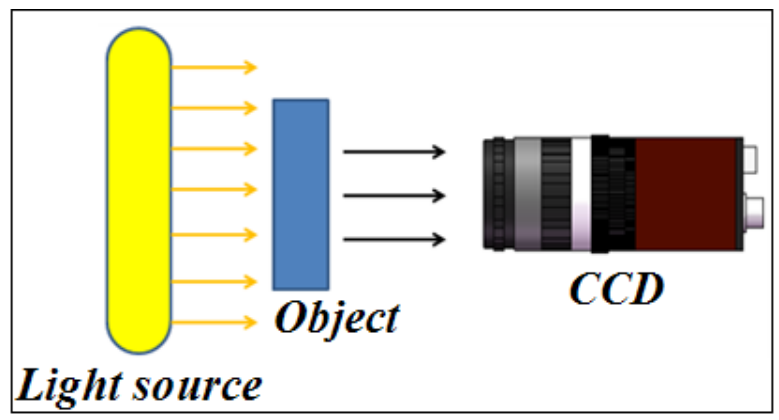

Figure 4. "Back light source".

\subsection{Measurement parameters of a saw blade milling cutter}

The saw blade milling cutter which has been measured by the developed inspection system is demonstrated in figure 5 . The goal of this investigation is to determine the following parameters of a saw blade milling cutter (K\&W, 2009; JIM DANDY TECHNOLOGY, 2009): tooth pitch, processing height, height of a full tooth, radius of a tooth top and pressure angle (Fig. 6).

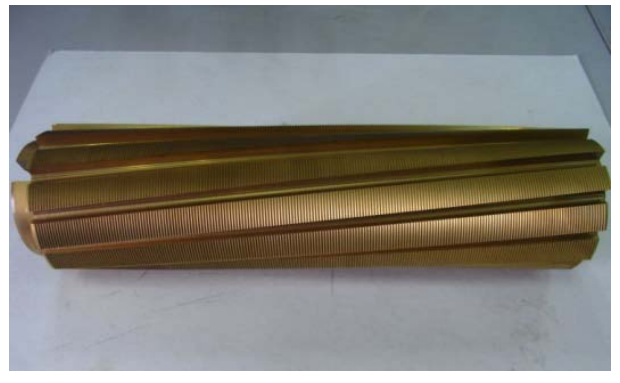

Figure 5. "Saw blade milling cutter".

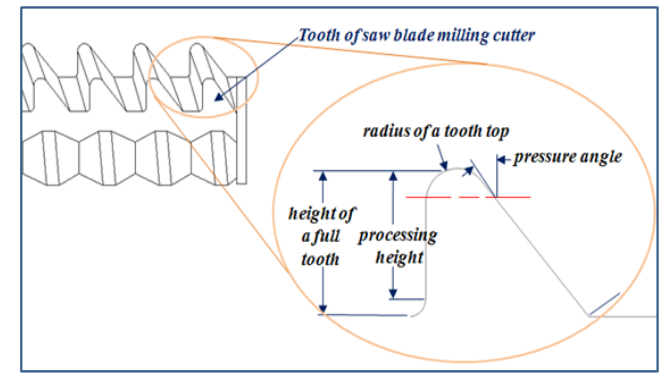

Figure 6. "The measurement parameters of a saw blade milling cutter".

The major measured angles of the saw blade milling cutter are rake angle, lead angle and helix angle. Hence, analysis of the angle's error need to be processed in the first and then according three errors measurement stage and measured dimensional parameters of the saw blade milling cutter can be set up (Table1). 


\begin{tabular}{|c|l|l|}
\hline Angle & \multicolumn{1}{|c|}{ Measuring process } \\
\hline Rake Angle & $\begin{array}{l}\text { Controlling the rotary axis of motor to rotate saw blade } \\
\text { milling cutter }\end{array}$ \\
\hline Lead Angle & $\begin{array}{l}\text { Controlling the stage, and rotating an angle of CCD with } \\
\text { the lead angle simultaneously }\end{array}$ \\
\hline Helix Angle & \begin{tabular}{l} 
Headingle \\
\hline Helingle
\end{tabular} & $\begin{array}{l}\text { Calculating the errors of helix curves for image } \\
\text { projection (Eq.2) }\end{array}$ \\
\hline
\end{tabular}

Table 1. "Measured angles".

$$
E=\frac{\left[\sum_{i=1}^{n} L_{i}-L_{i} \cos \left(\theta_{E}\right)\right]}{n}
$$

Equation 2. "Equation of errors of helix curves".

\section{Radius of a tooth top}

The circular distribution on a saw blade milling cutter (Fig.7) can be approximately described with a second-order equation (Eq.3). By some measured points $\left(x_{1}, y_{1}\right), \cdots,\left(x_{n}, y_{n}\right)$ on this circle and the least squares circle method (Eq.4), coefficients $a, b$ and $c$ of this equation can be determined. The circle center and the radius of a tooth top can be estimated by equation 5 .

$$
E_{i}=X_{i}^{2}+Y_{i}^{2}+a X_{i}+b Y_{i}+c
$$

Equation 3. "Equation of circular distribution on a saw blade milling cutter".

$$
\left[\begin{array}{ccc}
\sum X_{i}^{2} & \sum X_{i} Y_{i} & \sum X_{i} \\
\sum X_{i} Y_{i} & \sum Y_{i}^{2} & \sum Y_{i} \\
\sum X_{i} & \sum Y_{i} & \sum 1
\end{array}\right]\left[\begin{array}{c}
a \\
b \\
c
\end{array}\right]=\left[\begin{array}{l}
-\sum\left(X_{i}^{2}+Y_{i}^{2}\right) X_{i} \\
-\sum\left(X_{i}^{2}+Y_{i}^{2}\right) Y_{i} \\
-\sum\left(X_{i}^{2}+Y_{i}^{2}\right)
\end{array}\right]
$$

Equation 4. "Equation of circle and the least squares circle method". 


$$
\mathrm{o}=\left(\frac{\mathrm{a}}{2}, \frac{\mathrm{b}}{2}\right) ; \quad \mathrm{r}=\frac{\sqrt{\mathrm{a}^{2}+\mathrm{b}^{2} \quad 4 \mathrm{c}}}{2}
$$

Equation 5. "Equation of circle center and the radius of a tooth top".

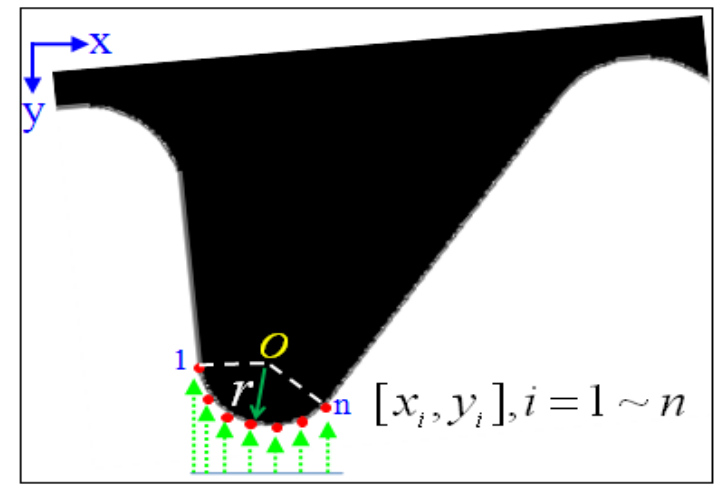

Figure 7. "Radius of tooth top r".

\section{Pressure angle}

The pressure angle is the slope of the oblique line (Fig.8). By some measured points $\left(x_{1}, y_{1}\right), \cdots,\left(x_{n}, y_{n}\right)$ on this line and the least square method (Eq.6), the oblique line equation can be derived. From the arc tangent of the oblique line, the pressure angle can be determined (Eq.7).

$$
\left[\begin{array}{cc}
\sum X_{i}^{2} & \sum X_{i} \\
\sum X_{i} & \sum 1
\end{array}\right]\left[\begin{array}{l}
a \\
b
\end{array}\right]=\left[\begin{array}{c}
\sum X_{i} Y_{i} \\
\sum Y_{i}
\end{array}\right]
$$

Equation 6. "Equation of line and the least square method".

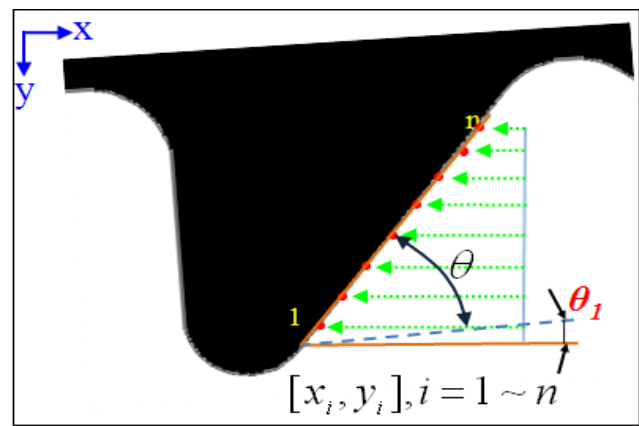

Figure 8. "Pressure angle $\theta$ ". 


$$
\theta=\left(\tan ^{-1} a\right)-\theta_{1}
$$

Equation 7. "Equation of pressure angle".

\section{Height of a full tooth}

The height of a full tooth $\mathrm{H}$ is defined by the length between the highest and lower point of arc-curves within a pitch of the saw (Fig.9). By the least squares method (Eq.4), the radius of a tooth top and tooth root can be solved. With the radius and the equation 8 and 9 , the $x, y$ coordinate positions of point $F$ and $D$ can be decided. The $y$ value difference (Eq.10) between point $F$ and $D$ signifies the length of the height of a full tooth.

$$
D=\left[-\frac{a_{1}}{2},-\left(\frac{b_{1}}{2}+r_{1}\right)\right]
$$

Equation 8. "Equation of position D".

$$
F=\left[-\frac{a_{2}}{2},-\left(\frac{b_{2}}{2}-r_{2}\right)\right]
$$

Equation 9. "Equation of position $\mathbf{F}$ ".

$$
H=\left(D_{y}-F_{y}\right) \times \cos \theta_{H}
$$

Equation 10. "Equation of the height of a full tooth".

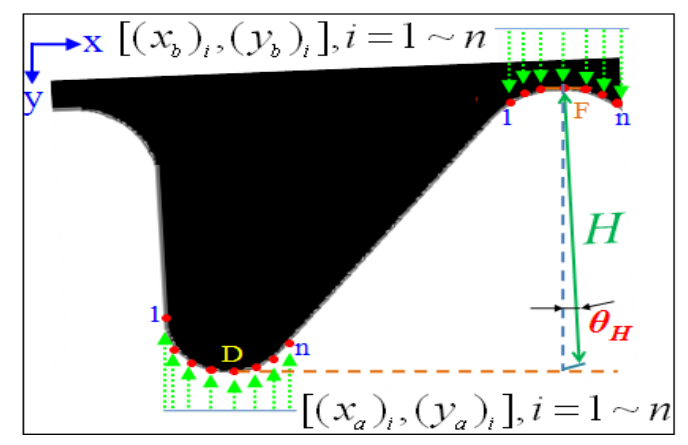

Figure 9. "All tooth stature $\mathbf{H " .}$ 


\section{Processing height}

By the least squares method (Eq.4,7), the intersection position $D$ and $E$ and their $\mathrm{x} / \mathrm{y}$ coordinate positions (Fig. 10) can be calculated. The y value difference (Eq.11) between point $E$ and $D$ reveals the processing height.

$$
h=\left(D_{y}-E_{y}\right) \times \cos \theta_{h}
$$

Equation 11. "Equation of the processing height"

\section{Tooth pitch}

After the Otsu's method and image threshold processing, some position data of points $\left(x_{1}, y_{1}\right), \cdots,\left(x_{n}, y_{n}\right)$ of the straight line and an oblique line of a saw blade milling cutter (Fig. 11) can be obtained. By least square method (Eq.7) the coefficient $a$ and $b$ can be derived. The pitch $p$ of a saw blade milling cutter will be calculated by position data of point K and L (Eq. 12).

$$
P=\sqrt{\left(x_{A}-x_{B}\right)^{2}+\left(y_{A}-y_{B}\right)^{2}}
$$

Equation 12. "Equation of the tooth pitch".

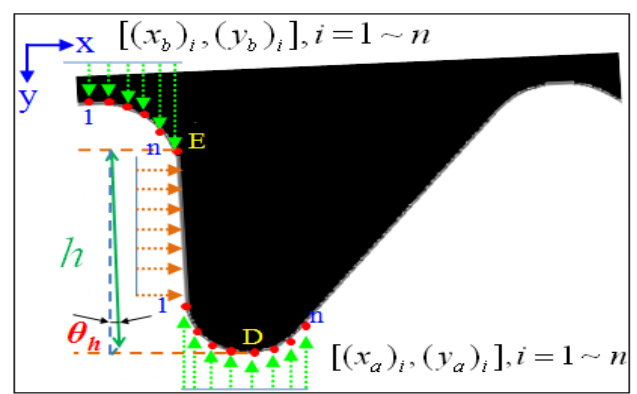

Figure 10. "Processing height $\mathbf{h}$ ".

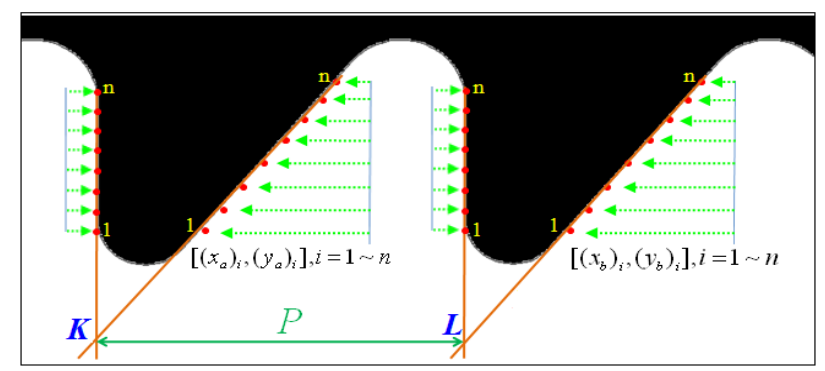

Figure 11. "Tooth pitch P". 


\section{Structure of measurement system}

The major components of this developed measurement system include the image acquisition device, the saw blade milling cutter's fixture and a self-constructed measurement program. A measured saw blade milling cutter is fixed on the fixture that is driven by the server motor, as shown in Fig. 12. The saw blade milling cutter's image can be acquired through the CCD and then by the measurement program the saw blade milling cutter's dimensions can be automatically measured. After the analysis of the program, dimensional parameters will be determined and represented (Fig. 13).

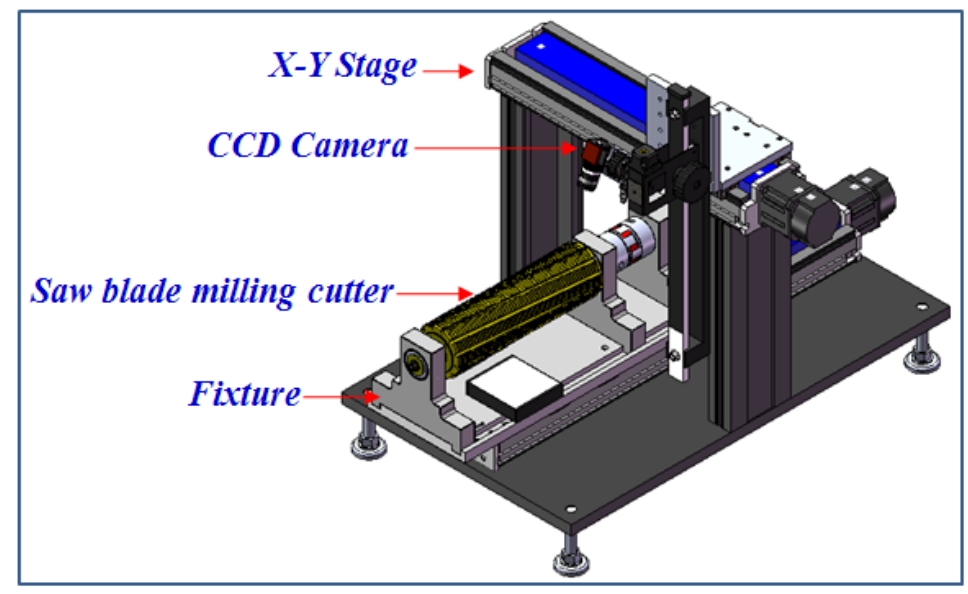

Figure 12. "Structure of measurement system".

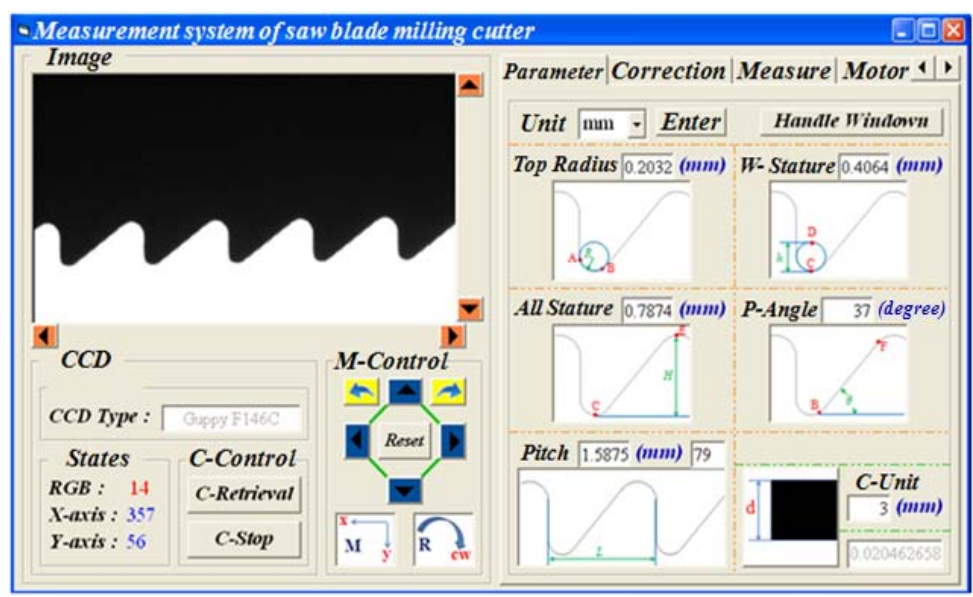

Figure 13. "Measurement program". 


\section{Results and analysis}

\subsection{Accuracy verification}

To verify the measurement accuracy of the image measurement system, ten teeth in front, middle and hind area of the measuring object have been measured. These measurement results have been compared with that of the same saw blade milling cutter obtain by a Coordinate Measuring Machine. They are listed in table 2, 3, and 4. From the experimental data, it can be derived that the dimensional accuracy is less than $25 \mu \mathrm{m}(2 \sigma)$ and the angular accuracy less than $0.26^{\circ}(2 \sigma)$. That is very accurate and can meet the industrial requirement for parameter measurements of the saw blade milling cutter.

\subsection{Experimental results of a saw blade milling cutter}

According the former described methods and procedures, some experiments for a saw blade milling cutter have been performed. The experimental results are shown in table 5.

By the measurement system analysis (MSA) (Yang, Marefat, \& Ciarallo, 1998; Santo, Liguori, Paolillo, \& Pietrosanto, 2004), the standard deviations of dimensional parameters are less than $25 \mu \mathrm{m}$ and that of the angular parameter less than $0.2^{\circ}$. That can be satisfied for the measurement requirement of the saw blade milling cutter.

\section{Conclusion}

In this investigation, an image inspection system has been developed for dimensional and angular measurements of the saw blade milling cutter. The measurement accuracy and standard deviation of the system have been verified and analyzed.

By the combination of the image acquisition device, the mechanical fixture and measurement program, an efficient and accurate image measurement system has been constructed. The quality control and precision of the saw blade milling cutter will be enhanced by this system which will be benefic equipment for manufactures of the saw blade milling cutter. 
The experimental results and analyses have proved that the measurement performance of this developed system is outstanding. Its dimensional accuracy is less than $25 \mu \mathrm{m}$ and angular accuracy less than $0.26^{\circ}$. The accurate measurement characteristic could meet the processing requirement of the saw blade milling cutter.

\begin{tabular}{|c|c|c|c|}
\hline $\begin{array}{c}\text { Measurement } \\
\text { parameter }\end{array}$ & $\begin{array}{c}\text { mean value of } \\
\text { measurement results by } \\
\text { CMM }\end{array}$ & $\begin{array}{c}\text { mean value of } \\
\text { measurement results by } \\
\text { the developed system }\end{array}$ & Difference \\
\hline Radius of a tooth top & $0.1654(\mathrm{~mm})$ & $0.1898(\mathrm{~mm})$ & $0.0244(\mathrm{~mm})$ \\
\hline Processing height & $0.3308(\mathrm{~mm})$ & $0.3796(\mathrm{~mm})$ & $0.0244(\mathrm{~mm})$ \\
\hline Height of a full tooth & $0.7964(\mathrm{~mm})$ & $0.7766(\mathrm{~mm})$ & $0.0198(\mathrm{~mm})$ \\
\hline Pressure angle & $38.71($ degree $)$ & $38.45($ degree $)$ & $0.26($ degree $)$ \\
\hline Tooth pitch & $1.3722(\mathrm{~mm})$ & $1.3541(\mathrm{~mm})$ & $0.0181(\mathrm{~mm})$ \\
\hline
\end{tabular}

Table 2. "Accuracy analysis (front ten teeth)".

\begin{tabular}{|c|c|c|c|}
\hline $\begin{array}{c}\text { Measurement } \\
\text { parameter }\end{array}$ & $\begin{array}{c}\text { mean value of } \\
\text { measurement results by } \\
\text { CMM }\end{array}$ & $\begin{array}{c}\text { mean value of } \\
\text { measurement results by } \\
\text { the developed system }\end{array}$ & Difference \\
\hline Radius of a tooth top & $0.1651(\mathrm{~mm})$ & $0.1903(\mathrm{~mm})$ & $0.0252(\mathrm{~mm})$ \\
\hline Processing height & $0.3302(\mathrm{~mm})$ & $0.3806(\mathrm{~mm})$ & $0.0252(\mathrm{~mm})$ \\
\hline Height of a full tooth & $0.8096(\mathrm{~mm})$ & $0.7889(\mathrm{~mm})$ & $0.0207(\mathrm{~mm})$ \\
\hline Pressure angle & $38.48($ degree $)$ & $38.6($ degree $)$ & $0.12($ degree $)$ \\
\hline Tooth pitch & $1.3528(\mathrm{~mm})$ & $1.3731(\mathrm{~mm})$ & $0.0203(\mathrm{~mm})$ \\
\hline
\end{tabular}

Table 3. "Accuracy analysis (middle ten teeth)".

\begin{tabular}{|c|c|c|c|}
\hline $\begin{array}{c}\text { Measurement } \\
\text { parameter }\end{array}$ & $\begin{array}{c}\text { mean value of } \\
\text { measurement results by } \\
\text { CMM }\end{array}$ & $\begin{array}{c}\text { mean value of } \\
\text { measurement results by } \\
\text { the developed system }\end{array}$ & Difference \\
\hline Radius of a tooth top & $0.1701(\mathrm{~mm})$ & $0.1899(\mathrm{~mm})$ & $0.0198(\mathrm{~mm})$ \\
\hline Processing height & $0.3402(\mathrm{~mm})$ & $0.3798(\mathrm{~mm})$ & $0.0198(\mathrm{~mm})$ \\
\hline Height of a full tooth & $0.8047(\mathrm{~mm})$ & $0.7881(\mathrm{~mm})$ & $0.0166(\mathrm{~mm})$ \\
\hline Pressure angle & $38.72($ degree $)$ & $38.51($ degree $)$ & $0.21($ degree $)$ \\
\hline Tooth pitch & $1.3842(\mathrm{~mm})$ & $1.4018(\mathrm{~mm})$ & $0.0176(\mathrm{~mm})$ \\
\hline
\end{tabular}

Table 4. "Accuracy analysis (hind ten teeth)".

\begin{tabular}{|c|c|c|}
\hline Measurement parameter & Mean value & Experimental standard deviation \\
\hline Radius of a tooth top & $0.1669(\mathrm{~mm})$ & $0.019(\mathrm{~mm})$ \\
\hline Processing height & $0.3337(\mathrm{~mm})$ & $0.021(\mathrm{~mm})$ \\
\hline Height of a full tooth & $0.8036(\mathrm{~mm})$ & $0.025(\mathrm{~mm})$ \\
\hline Pressure angle & $37.23($ degree$)$ & $0.2($ degree$)$ \\
\hline
\end{tabular}

Table 5. "Mean value and experimental standard deviation of measurement results".

\section{References}

Gonzalez, R.C., \& Woods, R.E. (2002). Digital Image Processing. (pp. 230-243). Prentice-Hall, Inc. 
Otsu, N. (1979). A threshold selection method fromgray-level histograms. IEEE Transaction System Man Cybernet, 9(1), 62-69. doi: 10.1109/TSMC.1979.4310076

Wang, Y.-C., Chang, C.-C., Lin, J.-C., Lee, B.-Y., \& Lin, W.-S. (2009). Proceedings of the 2009 WRI Global congress on intelligent systems, Vol III, 24-27.

Scaman, M.E., \& Economikos, L. (1995). Computer vision for automatic inspection of complex metal patterns on multichip modules (MCM-D), IEEE Trans. On Components, Packaging and Manufacturing Technology, Part B. Advanced Packaging, 18(4), 675-684.

K\&W (2009). A Slice of Life, Product Information, Retrieved from http://www.kwtools. biz.

JIM DANDY TECHNOLOGY CO., LTD. (2009). Product Information, Retrieved from http://www.j-dandy.com/english/html/philosophy.htm

Yang, C.C., Marefat M.M., \& Ciarallo, F.W. (1998). Error analysis and planning accuracy for dimensional measurement in active vision inspection. IEEE Transaction on Robotics and Automation, 14(3), 476-487. doi: $10.1109 / 70.678456$

Santo, M.D., Liguori, C., Paolillo, A., \& Pietrosanto A. (2004). Standard uncertainty evaluation in image-based measurements. Measurement, 36, 347-358. doi: 10.1016/j.measurement.2004.09.011 